\title{
Impact of Tourism on Retail Shopping in Dubai
}

\author{
Shreyans Mehta, Anshul Jain, and Rahul Jawale
}

\begin{abstract}
One of the most lucrative tourism activities is shopping. Dubai is one of the most famous and popular tourist shopping destinations. This research report shows the study of factors and existing trends in tourism which affects retail shopping in Dubai. The behavior of tourist with respect to retail shopping is examined.

The research revolves around the tourists coming to Dubai and tries to identify the possible reasons as to why they chose Dubai as their holiday destination. The various factors such as infrastructure of Shopping destinations, Hotels and the branding strategy followed in Dubai. Survey was conducted on a set of focused groups and a list of questions followed the survey to build enough evidence for obtaining insights in the research. Out of a list of various factors which might be reasonable enough for a tourist to come to Dubai, retail shopping was found out to be most significant. As the emerging of Dubai shopping malls along with various shopping festivals, tourists flock to Dubai in an urge to do shopping. Initially when tourist visited Dubai for retail shopping their main emphasis was on price and discount factor. But, this is gradually changing. Another set of survey questions tried to gauge the factor which promoted retail shopping in Dubai. By analyzing the survey results with the help of Discriminant analysis we obtained that 'brand presence' followed by 'variety' were the most significant factors. Thereby concluding, recent trends for Dubai tourism suggests that tourists behavior is changing as 'brand presence' and 'variety' are more significant as compared to 'price' and 'discounts'.
\end{abstract}

Index Terms-Dubai, retail shopping, tourism.

\section{INTRODUCTION}

Our concentration in this research project is on Dubai as a retail shopping destination for tourist and its effect on the economy of Dubai. The major portion of tourism is formed by the Leisure sector in Dubai. In this research we are taking into consideration Shopping aspect of the tourism industry.

In the Middle East region Dubai is the most popular shopping destination. Worldwide, shopping is considered as one of the most attractive activities. Retail sector in accordance with Government of Dubai has established various shopping events including Dubai shopping festival, Dubai summer surprises and many more to lure tourists. Shopping has been acknowledged to be a common tourist activity and a motivation for travel, especially in the case of cross-border trips. Factors like lower prices, lower taxes, and larger variety of goods, extensive promotion and media coverage encourage tourist to shop in a different country [1].

Manuscript received June 5, 2014; revised August 21, 2014. This work was supported in part by the SP Jain School of Global Management.

The authors are with the SP Jain School of Global Management 5 , Figtree Drive, Sydney Olympic Park, NSW, 2127, Australia (email:Shreyans.mjan14@spjain.org, anshul.mjan14@spjain.org, rahul.mjan14@spjain.org).
One of the main reasons of tourists visiting Dubai is to shop at various malls mainly in the Dubai's old market which is referred as Souk market, Gold Souk being one of the most famous among them. Significant amount of revenue is contributed to retail industry through tourists. Dubai has more than 70 shopping centers. It is regarded as the shopping capital of Middle East region. Thus there definitely existed a need to understand and study the impact of tourism on retail shopping in Dubai.

The experience of shopping is more significant in Dubai malls as these attract shoppers from higher socio-economic strata who expect higher standards of service and experience as compared to the shoppers who visit malls in many developing countries. In malls, Superior shopping experience is being created by aligning their management philosophy and practices perfectly with the expectations of shoppers [2].

Dubai Department of Tourism and Commerce Marketing have played a crucial role in making Dubai as one of the favorite tourist destination. It was well understood by the Dubai government that Tourism would actuate economic development and lure people from across the world to make Dubai as their second home. As Dubai government worked towards building infrastructure, Dubai Department of Tourism and Commerce Marketing focused on exploring new ideas for expansion of tourism [3].

However, for the growth of Dubai, the government of Dubai understood that tourism and shopping alone will not sustain, this led to the inception of business tourism in Dubai. Thus to fulfill the needs of business tourism, Dubai World Trade Centre, Dubai International Financial Centre were constructed. In order to encourage investments from the foreign company's free zones were also established along with the provision of full tax exemption. As a result, more international visitors were attracted towards this. Much infrastructural advancement also included building of one of the busiest airports in the world. Thus in order to cater the need of growing tourism a new airport is currently under construction [4].

\section{Research Methodology}

\section{A. Research Objectives}

- To study factors influencing tourism and retail shopping experience in Dubai.

- To study existing trends in tourism and retail shopping sector in Dubai.

- To study the tourist's behavior with respect to retail shopping in Dubai.

\section{B. Statistical Tool Used}

Discriminant functional analysis was used to predict the categorical dependent variable by using multiple 
independent variables. The data fed for discriminant analysis consisted of the data obtained from a sample of 91 on different variables. Our objective of discriminant analysis is to build a predictive model for a given sample data based on the observed characteristics in that sample. These observed characteristics can be the ways in which the data has been categorized in the given sample. Once the predictive model is built, we have then applied it to new data to get a decision which is significantly similar to the observed characteristics of the given sample.

\section{LITERATURE REVIEW}

Dubai plays a host to millions of tourists around the year, out of which many stays with friends, others with families and in hotels and apartments. In Dubai there are 573 hotels and hotel apartments ranging from luxurious five-star hotels to unrated hotels [3].

TABLE I: STATISTICS OF TOURISTS ARRIVING IN DUBAI [5]

\begin{tabular}{|l|c|c|c|}
\hline Source Market & $\begin{array}{l}\text { Number of } \\
\text { guests (First } \\
\text { half of 2013) }\end{array}$ & $\begin{array}{l}\text { Number of } \\
\text { guests (First } \\
\text { half of 2012) }\end{array}$ & $\begin{array}{l}\text { \% } \\
\text { Increase }\end{array}$ \\
\hline GCC & 1672084 & 1436742 & 16.4 \\
\hline Europe & 1505646 & 1365656 & 10.3 \\
\hline South Asia & 795108 & 784366 & 1.4 \\
\hline Far East Asia & 360473 & 336057 & 7.3 \\
\hline $\begin{array}{l}\text { North America, } \\
\text { Canada and } \\
\text { Mexico }\end{array}$ & 300274 & 297338 & 1 \\
\hline Australia & 131202 & 109348 & 20 \\
\hline South America & 61066 & 51743 & 18 \\
\hline Africa & 278613 & 259208 & 7.5 \\
\hline $\begin{array}{l}\text { Other Arabic } \\
\text { Countries }\end{array}$ & 478912 & 386765 & 23.8 \\
\hline
\end{tabular}

Till date Dubai Shopping Festival has hosted over 50 million visitors. Around 4000 or more retailers and shops take part in this event. Massive discounts close to around $70-80 \%$ are given by the shops during this festival. Dubai has an advantage of strategic location midway between Asia, Africa and Europe. Dubai can be reached by flight in just about three hours from Mumbai (India), eight hours from Hong Kong, and an overnight flight from London [6]. Tourism destinations across the world have been competing to attract international tourists and thus resulting in economic impact and tourism development. It is seen as a way of improving a country's economic and social wellbeing [7].

Tourism policy and planning in Dubai follows the hybrid state-controlled/integrated tourism which is dependent on the political stability and the vision of the ruler of Dubai. The role of strategic vision in branding a destination has highlighted the importance of the 6P's namely purpose, people, performance, products, positioning and process in destination branding. The findings proposed that Dubai does not have a key image differentiator which would stand apart from others and stressed on the need to focus on the branding strategy [8].

Passenger footfall at Dubai International Airport has increased from an annual figure of 40.9 million passengers in 2009 to 47.2 million in 2010. Passengers are projected to cross 98 million by 2020 [9].

Dubai has the most developed tourism infrastructure in the Middle East and North Africa region and is thus capable of welcoming large numbers of tourists.

The city is one of the best connected cities in the world with air transportation networks reaching out to all continents, mainly thanks to its local carrier Emirates Airlines. Dubai suffers strong seasonality in tourism as the hot summer months see many of its population flee back to their home countries to avoid temperatures of 50 degrees Celsius.All over the world tourism industries are labour and income intensive, which translates major amount of sales into income and corresponding jobs [10].

Dubai is increasingly known for its high cost of living, with restaurants, hotels and all facilities being far more expensive than in most regional tourism destinations. Despite trying to change this, high prices prevail. Dubai is strongly dependent on energy, which is used to keep the city air-conditioned, and to run cars and much more. Without this, the Emirate would not survive or be able to welcome tourists at all. Innovation is the solution. Despite a rise in the number of tourists, the length of stay remains rather limited at an average of three days adding more tourist attractions.

Duty free and no tax policy are attracting more and more tourists all over the world. Most of the laws are being made for tourist safety. As far as regulations are concerned duty free shopping is one of the main attractions among them.

Culture and cultural heritage are prominent resources in any society. Dubai sustains cultural heritage in form of Dubai Museum and souks. Dubai museum gets lots of visitors every year and lots of foreign people try to engage in its culture and tradition by visiting souks and dessert safari.

Dubai is considered as one of the safest place in Gulf corporation council. Many of the international tourists visit Mosques, trying to understand culture \& traditions. Religious tourism has grown rapidly over a period of years in United Arab Emirate, the pilgrims visiting Mecca \& Medina often halt in Dubai and Abu Dhabi during their Journey.

Tourism growth in Dubai has attracted number of international brands which has helped locals improve their lifestyle. Though Dubai is a tourism centric city, there are laws defined for tourists to follow in order to avoid any conflicts. The majority of the tourist visitors are working class travelers in the age group of 35-49 followed by $25-34$ for both the business and leisure. Dubai's demand is rising among young generation in the age bracket of 22-35, as it provides both work opportunities and leisure at the same time. Dubai's infrastructure is designed to cater luxury oriented tourists along with business sector. But at the same time Dubai offers activities to meet the demand of middle income travelers. Dubai offers lots of things for everyone, from high spending luxury conscious to budget conscious traveler. Tourists from all segments visit Dubai and Dubai offers something for everyone. To maintain the sustainability of the tourism throughout the year, lot of investments have been made in infrastructure to attract tourists throughout the year including arrangement of Shopping festivals, sports events, Business events.

Dubai has been investing throughout to offer various 
options for tourists in all the seasons including special events as Dubai world cup, Gulf food exhibition and various festivals throughout the season. Various infrastructural projects are coming up with huge requirements of workforce, and this will not only increase business tourism but also help sustain increasing demand for infrastructural growth.

Department of Tourism and Commerce Marketing is seeking to diversify the tourism base by reaching out to emerging markets in Africa, Latin America and Asia, targeting high spenders in these markets. It is also building a new "University and National Museum" for tourist attraction. World's tallest commercial tower to be built in Jumeirah Lake Towers, and is to be given the name "Burj $2020 "$ in honor of the World Expo 2020.It has also given a financial incentive to Hotel investment Industry for developing more 3 and 4 star hotels. In Dubai, new businessmen can penetrate and distribute a new product market as it has an organized retail sector as compared to other developing nations. People from various parts of the world fly to Dubai to grab unbeatable deals. Not only people, but also various upcoming brands are getting attracted to promote their brands. Promotions and offers are the only the most prominent factor for Dubai to promote itself as a tourist destination.

Dubai has a market for every segment of the society. Retail Market is for everyone according to his/her income. The Location of Dubai has played a significant role in increased retail sales. People from Europe and South Asian countries halt at Dubai during their trips to other countries to take some out to grab an experience of entertainment and events happening across Dubai. Dubai Shopping Festival is the key to tourism. Dubai has evolved as a tourist destination due to the increased tourist migration of tourists during the festival. Dubai shopping festival has slowly and steadily started to expand its horizons as earlier Dubai shopping festival used to run for one month but now due to increased tourism, it runs extensively for three months.
Dubai has a large centre of women centric products. From apparel industry to gold souks, Dubai provides everything that a women desires. It is evident that the collection of women apparel is more as compared to men's stock. Women have been the focus of the nation as Dubai tries to improvise its image in global market. Women not only buys products for herself, but they extensively purchase products for their family, children, parents and husbands which in comparison a male counterpart does less. Basically people from all segments prefer to shop. But it is evident that Dubai has been focusing on capturing the market for old people coming from Europe and America's with their families. As these people can afford luxury products as compared to other age groups, the recent focus is on that market segment. Pricing is different is different malls as it needs to cater every segment of the society.

Dubai is a global market for trade and commerce. Right from first copy product to premium brands are available here. Saudi Arabia has been a major contributor to Dubai tourism. People from Saudi come to Dubai to spend weekends and to buy luxury and expensive products which are not easily accessible in their own country. Few of the retail sectors, includes Electronics and appliance specialist retailers, department stores, and apparel specialist retailers. They are the most beneficiary of the rise in tourist arrivals in 2012 , with all channels recording an increase of $6 \%$, thus outperforming overall retailing sales. Tourists will be the greater proportion of consumers in Dubai and thereby over the forecast period, it will significantly contribute towards the growth of retail value sales. In case of high-end or department stores, luxury retailers and jewelry showrooms, this holds true. As per compound annual growth rate, there will be an expansion of the departmental store by a constant value $7 \%$ over the estimate period, while watch specialist retailers, jewelry and apparel specialist retailers will record a constant value compound annual growth rate of $5 \%$. Consequently, focus is driven to the diverse and international customer base by these retailing channels [9].

TABLE II: STATISTICS TO DETERMINE WHICH FACTOR IS AFFECTING TOURISTS TO COME BACK TO DUBAI

\begin{tabular}{|c|c|c|c|c|c|}
\hline \multirow[b]{2}{*}{ Tourist Visiting Again } & \multirow[b]{2}{*}{ Factors } & \multirow[b]{2}{*}{ Mean } & \multirow[b]{2}{*}{ Standard Deviation } & \multicolumn{2}{|c|}{ Valid N (Listwise) } \\
\hline & & & & Unweighted & Weighted \\
\hline \multirow{5}{*}{$\mathbf{0}$} & factor_retail shopping & 2.2222 & 1.20185 & 9 & 9.000 \\
\hline & factor_leisure & 3.2222 & 0.83333 & 9 & 9.000 \\
\hline & factor_hospitality & 2.3333 & 1.11803 & 9 & 9.000 \\
\hline & factor_business & 2.3333 & 0.86603 & 9 & 9.000 \\
\hline & factor_extremity & 3.0000 & 1.00000 & 9 & 9.000 \\
\hline \multirow{5}{*}{1} & factor_retail shopping & 3.2375 & 1.02183 & 80 & 80.000 \\
\hline & factor_leisure & 2.9500 & 0.80975 & 80 & 80.000 \\
\hline & factor_hospitality & 2.4375 & 0.82437 & 80 & 80.000 \\
\hline & factor_business & 2.4250 & 0.88267 & 80 & 80.000 \\
\hline & factor_extremity & 3.1000 & 0.80505 & 80 & 80.000 \\
\hline \multirow{5}{*}{ Total } & factor_retail shopping & 3.1348 & 1.07863 & 89 & 89.000 \\
\hline & factor_leisure & 2.9775 & 0.81153 & 89 & 89.000 \\
\hline & factor_hospitality & 2.4270 & 0.85130 & 89 & 89.000 \\
\hline & factor_business & 2.4157 & 0.87658 & 89 & 89.000 \\
\hline & factor_extremity & 3.0899 & 0.82076 & 89 & 89.000 \\
\hline
\end{tabular}




\section{FINDINGS AND ANALYSIS}

Dependent variables in case of our project are the responses of the tourist taken from the survey i.e. whether tourist would like to visit Dubai again. The responses are converted into numerical format. 'Yes' response as ' 1 ' and 'No' response as ' 0 '.

Independent variables for factors affecting tourist to come back to Dubai were taken as Retail Shopping, Leisure, Hospitality, Business and Extremity.

The factors affecting tourism choice of shopping destination includes: Strategic Location, Society and culture, Retail, Tourism Infrastructure, Promotions, Attractions and events, Economic and Tourism Policy.

Variables which affected tourism included: Age, Gender, Geographic locality, Occupation, Income, Environmental factors, social factors, cultural factors, tourist interest.

Variables which affected retail shopping included Price, Discount, Variety, Brand Presence, Exclusivity, Store layout and unique presentation.

A questionnaire was designed for the purpose of the study and the questionnaire included questions relating to the different variables which affect the tourists' behavior. It consisted of questions like preferred month of travel, willing to spend, period of stay, shopping experience, price fairness, shopping without festival season, recommendation of Dubai as a shopping tourist destination, attractiveness of prices, discounts, variety, brand presence, availability of high exclusive products, store layout and orientation.

\section{A. Factors Affecting Tourist to Come back to Dubai}

Table II shows that "retail shopping" has the highest standard deviation across all the variables which might influence tourist's preference of selecting Dubai to visit again. Thus, we concluded that among all the factors listed, "retail shopping" was the most prominent factor is affecting a tourist's choice of coming back to Dubai.

Table III, shows that retail shopping has the most significant value among all factors associated with tourists coming back to Dubai, as the significance value of retail shopping is $0.07 \%$ which is very less than significance value $5 \%$.

TABLE III: TESTS OF EQUALITY OF GROUP MEANS

TABLE III: TESTS OF EQUALITY OF GROUP MEANS
\begin{tabular}{|l|l|l|l|l|l|}
\hline \multicolumn{1}{|c}{ Factors } & $\begin{array}{c}\text { Wilks' } \\
\text { Lambda }\end{array}$ & F & df1 & df2 & Sig \\
\hline $\begin{array}{l}\text { factor_retail } \\
\text { shopping }\end{array}$ & 0.919 & 7.714 & 1 & 87 & 0.007 \\
\hline factor_leisure & 0.99 & 0.909 & 1 & 87 & 0.343 \\
\hline factor_hospitality & 0.999 & 0.12 & 1 & 87 & 0.730 \\
\hline factor_extremity & 0.999 & 0.088 & 1 & 87 & 0.768 \\
\hline factor_business & 0.999 & 0.119 & 1 & 87 & 0.731 \\
\hline
\end{tabular}

Table IV suggests that out of all the factors, retail shopping was the most significant factor in determining that what led the tourists to come back to Dubai. The value 0.696 is the highest value which suggests that this factor holds the maximum importance/significance in the analysis.

\begin{tabular}{|l|l|}
\hline \multicolumn{2}{|c}{ TABLE IV: STRUCTURE MATRIX } \\
\hline Factors & Function 1 \\
\hline factor_retail shopping & 0.696 \\
\hline factor_leisure & -0.239 \\
\hline factor_hospitality & 0.087 \\
\hline factor_extremity & 0.086 \\
\hline factor_business & 0.074 \\
\hline
\end{tabular}

TABLE V: WILKS' LAMBDA

\begin{tabular}{|c|r|r|r|c|}
\hline $\begin{array}{c}\text { Test of } \\
\text { Functions }\end{array}$ & $\begin{array}{r}\text { Wilks' } \\
\text { Lambda }\end{array}$ & Chi-Square & df & Sig \\
\hline 1 & 0.759 & 22.612 & 6 & 0.001 \\
\hline
\end{tabular}

Table V explains that the data obtained from the sources was valid and the significance value of $0.1 \%$ justifies this. Discriminant analyses suggest that Wilks' Lambda value is more that $75 \%$ which suggest the test holds for this data.

TABLE VI: STATISTICS TO DETERMINE WHICH FACTOR IS AFFECTING TOURISTS RETAIL SHOPPING

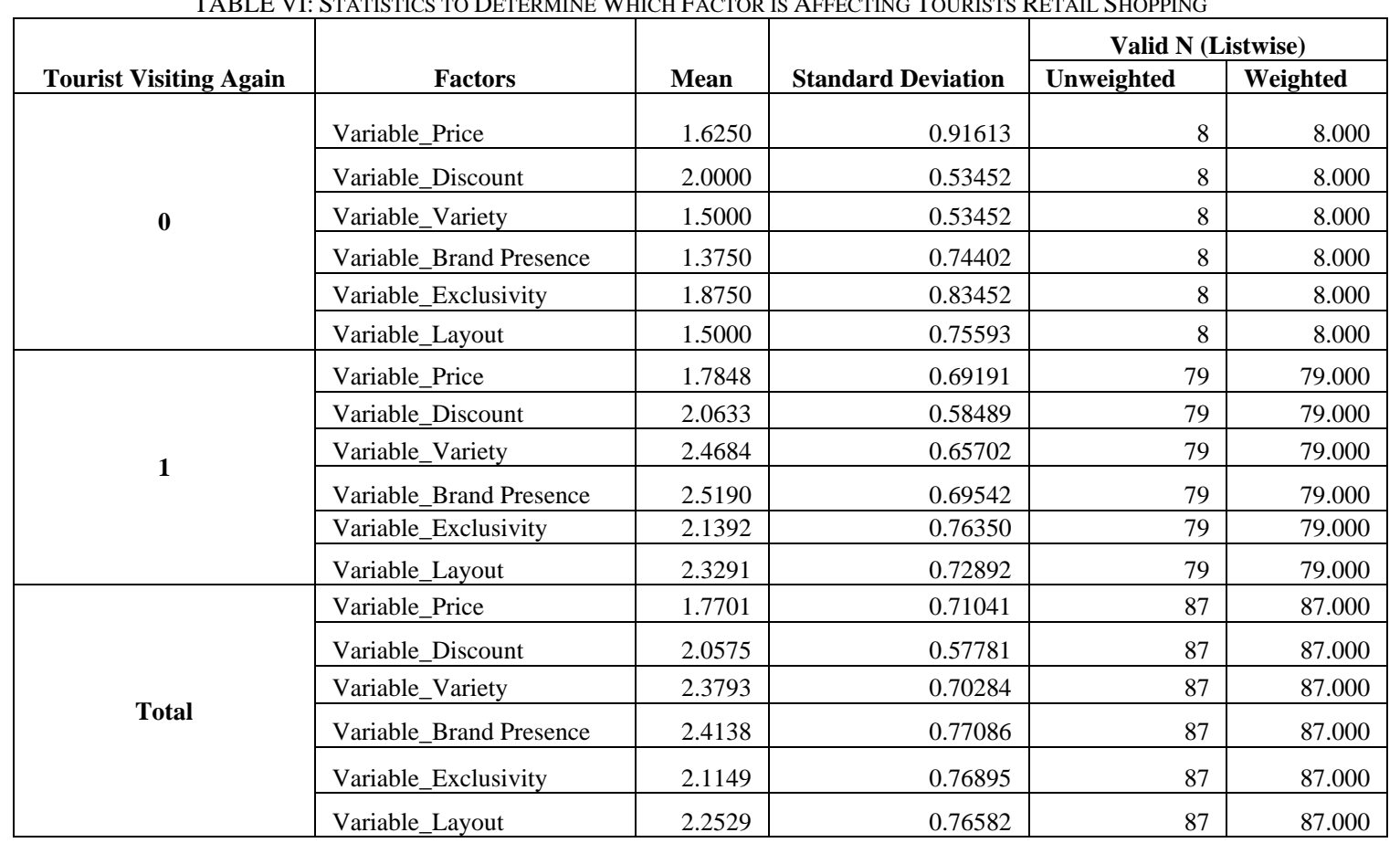




\section{B. Factors affecting Retail Shopping}

From Table VI provides the relation between various variables like price, discount, variety, brand presence, exclusivity and layout of the stores. It provides a set of mean and standard deviation for all the variables which might affect a retail shopping experience. The sample was tested for both "yes"(1.00) and "no"(.00) over all the variables. Through Discriminant Analysis it became evident that out of all the variables, brand presence is the most significant factor followed by variety and layout. The mean and standard deviation for brand presence was the highest among all the variables, which suggest its highest significance.

Table VII suggests that the brand presence is the most significant factor in the analysis. Wilki's lambda for brand presence is the lowest with $F$ value being highest in comparison to other variables makes it the best factor due to which retail shopping gets influenced. This suggests that in Dubai there is shift from price and discounts to the brand presence and variety quotient of the brands.

TABLE VII: TESTS OF EQUALITY OF GROUP MEANS
\begin{tabular}{|l|l|c|c|c|c|}
\hline \multicolumn{1}{|c}{ Factors } & $\begin{array}{c}\text { Wilks' } \\
\text { Lambda }\end{array}$ & F & df1 & $\mathbf{d f 2}$ & Sig \\
\hline Price & 0.996 & 0.365 & 1 & 85 & 0.547 \\
\hline Discount & 0.999 & 0.086 & 1 & 85 & 0.770 \\
\hline Variety & 0.84 & 16.23 & 1 & 85 & 0.000 \\
\hline $\begin{array}{l}\text { Brand } \\
\text { Presence }\end{array}$ & 0.814 & 19.43 & 1 & 85 & 0.000 \\
\hline Exclusivity & 0.99 & 0.856 & 1 & 85 & 0.357 \\
\hline Layout & 0.901 & 9.341 & 1 & 85 & 0.003 \\
\hline
\end{tabular}

TABLE VIII: STRUCTURE MATRIX

\begin{tabular}{|l|l|}
\hline Factors & Function 1 \\
\hline variable_brand presence & 0.848 \\
\hline variable_variety & 0.776 \\
\hline variable_layout & 0.588 \\
\hline variable_exclusivity & 0.178 \\
\hline variable_price & 0.116 \\
\hline variable_discount & 0.057 \\
\hline
\end{tabular}

Table VIII shows the most prominent variable in determining which factor is crucial in retail shopping that motivates the tourists to shop in Dubai. Out of the six variables, brand presence and variety are the most prominent factor. Earlier price and discount used to be a crucial factor, but now the trend is changing towards the brand availability and the variety which Dubai has to offer to its tourists.

\begin{tabular}{|l|c|c|c|c|}
\hline $\begin{array}{l}\text { TABLE IX: WILKS' LAMBDA } \\
\text { Functions of }\end{array}$ & $\begin{array}{c}\text { Wilks' } \\
\text { Lambda }\end{array}$ & Chi-Square & df & Sig \\
\hline 1 & 0.759 & 22.612 & 6 & 0.001 \\
\hline
\end{tabular}

Table IX suggest that the significance value from this data is $0.1 \%$, which is well below $5 \%$. Thus the test stands and results achieved from the test are significant. Also Wilks' Lambda value of more $75 \%$ suggests that the results are valid for more than $75 \%$ of the sample.

\section{CONCLUSION}

From the survey conducted it was observed that Retail shopping is the dominant factor among others to influence tourist to visit Dubai again, and Brand presence and variety are the dominant factors in the retail shopping that affects tourists decision of visiting again.

The trends in the tourism industry are changing with times, as it was observed that tourist nowadays not only travel from leisure or business perspective but also for shopping tourism. The general perspective of a shopper has changed over the years from prices or discounts to brand presence and variety offered.

The future scope for this project would be to calculate the impact of retail shopping tourism on the economy of Dubai. Any of the factors can be taken up by researchers' for further research and analysis to provide insights on the subject.

\section{ACKNOWLEDGMENT}

This research paper is made possible through the help and support from SP Jain School of Global Management. Especially, please allow me to dedicate my acknowledgment of gratitude toward the significant advisor and contributor: Mrs. Jyothsna Appaiah Singh. Thank you for the support and encouragement. She thoughtfully provided feedback on regular basis and offered invaluable detailed advices on formulating, designing and providing key insights towards reaching the objectives of the paper.

\section{REFERENCES}

[1] D. Timothy and R. Butler, "Cross-border shopping a North American perspective," Annals of Tourism Research, vol. 1, no. 22, pp. 16-34, 1995.

[2] H. Singh and V. Sahay, "Management of Indian shopping malls," Retail and Leisure Property, pp. 55-64, 2010.

[3] Department of Tourism \& Commerce Marketing. (22 February, 2014). 'Definitely Dubai': Dubai for tourism. [Online]. Available: http://dubaitourism.ae/

[4] Airports Council International. (22 February, 2014). International passenger traffic for the past 12 months': Airports council international. [Online]. Available: http://www.aci.aero/

[5] Department of Tourism and Commerce Marketing. (31 July, 2013). [Online]. Available: http://pr.dubaitourism.ae/2013/07/31/dubaienjoys-busiest-first-half-year-ever-attracting-5-5-million-visitors

[6] Definitely Dubai. 23 February 2014. [Online]. Available: http://www.definitelydubai.com/.

[7] G. Eccles, "Marketing sustainable development and international tourism," International Journal of Contemporary Hospitality Management, pp. 20-26, 1995.

[8] M. Balakrishnan, "Dubai - A star in the East. A case study in strategic destination branding," Journal of Place Management and Development, vol. 1, no. 22, pp. 62-91, 2008.

[9] Dubai International. (26 February, 2014). Fact sheets, reports \& statistics: Dubai airports. [Online]. Available: http://www.dubaiairports.ae/

[10] W. Matheieson, Tourism-Economic Physical and Social Impacts, 1992.

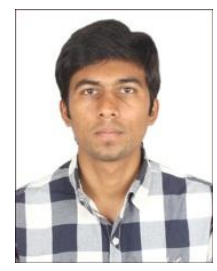

Shreyans Mehta was born in Akola, Maharashtra, India on July $21^{\text {st }} 1989$. Shreyans Mehta holds the bachelor degree of technology in information technology, from Gurunanak Engineering College, Hyderabad, Andhra Pradesh, India in 2011.

He has a 2.3 years' work experience. He was associated with Mphasis as a software engineer.

Mr. Mehta is a member of Public Relations Committee and Business Events Committee at SP Jain School of Global Management. Mr. Mehta is awarded International Software Testing 
Qualifications Board (ISTQB) certification from Certified Tester Foundation Level. Mr. Mehta has also received Proficiency Award in Bharatiya Vidhya Bhavan Public School.

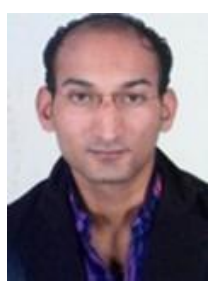

Anshul Jain was born in Jaipur, Rajasthan, India on February 5, 1991. Anshul graduated in electronics and communication engineering from Rajasthan Technical University in 2012, during which he was associated with major projects in 'Automation' and 'GPS Data logger'. Also, he presented a seminar on 'Data Compression Techniques'.

$\mathrm{He}$ did training in Vodafone in '3G-intracircle roaming and transmission techniques along with GSM

\section{architecture'.}

Mr. Jain is an active member of Industry Interface Committee and Scheduled Business Fest in Dubai for SP Jain.

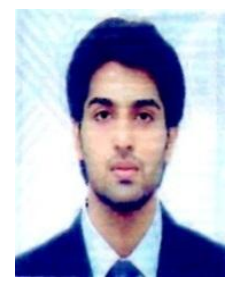

Rahul Jawale was born in Sinner, Maharashtra, India on May 22, 1987. Rahul Jawale holds a bachelor degree of engineering in electronics engineering, from MIT Engineering College, Pune, Maharashtra, India in 2012.

Mr. Jawale had been a member o Business Events Committee of IEEE at MIT engineering college.

Mr. Jawale has also received Proficiency Award at MIT engineering college. 